\title{
In vivoT cell activation in lymphoid tissues is inhibited in the oxygen-poor microenvironment
}

\section{Akio Ohta*, Rohan Diwanji, Radhika Kini, Meenakshi Subramanian, Akiko Ohta and Michail Sitkovsky}

New England Inflammation and Tissue Protection Institute, Northeastern University, Boston, MA, USA

Edited by:

Vladimir Brusic, Dana-Farber Cancer Institute, USA

\section{Reviewed by:}

Yousuke Takahama, University of

Tokushima, Japan

Paul M. Hwang, National Institutes of Health, USA

Koji Yasutomo, University of

Tokushima, Japan

*Correspondence:

Akio Ohta, Northeastern University, 113 Mugar Building, 360 Huntington Avenue, Boston, MA 02115, USA. e-mail:a.ohta@neu.edu

\begin{abstract}
Activation of immune cells is under control of immunological and physiological regulatory mechanisms to ensure adequate destruction of pathogens with the minimum collateral damage to "innocent" bystander cells. The concept of physiological negative regulation of immune response has been advocated based on the finding of the critical immunoregulatory role of extracellular adenosine. Local tissue oxygen tension was proposed to function as one of such physiological regulatory mechanisms of immune responses. In the current study, we utilized in vivo marker of local tissue hypoxia pimonidazole hydrochloride (Hypoxyprobe-1) in the flowcytometric analysis of oxygen levels to which lymphocytes are exposed in vivo. The level of exposure to hypoxia in vivo was low in B cells and the levels increased in the following order: T cells $<$ NKT cells $<$ NK cells. The thymus was more hypoxic than the spleen and lymph nodes, suggesting the variation in the degree of oxygenation among lymphoid organs and cell types in normal mice. Based on in vitro studies, tissue hypoxia has been assumed to be suppressive to T cell activation in vivo, but there was no direct evidence demonstrating that $T$ cells exposed to hypoxic environment in vivo are less activated. We tested whether the state of activation of $T$ cells in vivo changes due to their exposure to hypoxic tissue microenvironments. The parallel analysis of more hypoxic and less hypoxic T cells in the same mouse revealed that the degree of $T$ cell activation was significantly stronger in better-oxygenated T cells. These observations suggest that the extent ofT cell activation in vivo is dependent on their localization and is decreased in environment with low oxygen tension.
\end{abstract}

Keywords:T cell, oxygen, hypoxia, hyperoxia, Hypoxyprobe-1, cytometry, tumor

\section{INTRODUCTION}

In vitro studies of immune response have provided many critical insights into mechanisms of immune recognition. It was also realized, however, that the conventional in vitro cell culture is not suitable to studies of regulation of immune response since it does not faithfully reproduce the in vivo tissue microenvironments especially as it is related to in vivo oxygen tension (Braun et al., 2001; Caldwell et al., 2001). Although most of in vitro studies on immune responses have been conducted at normal ambient atmosphere $\left(21 \% \mathrm{O}_{2}\right)$, oxygen concentration in vivo is lower than this level. Mean oxygen tension drops from $\sim 100 \mathrm{mmHg}$ in arterial blood to $40 \mathrm{mmHg}$ in peripheral tissues (Semenza, 2003; Michiels, 2004). The oxygen tension further drops in inflamed tissue, probably because inflammation damages tissue vasculature and causes local hypoxia (Karhausen et al., 2005).

The degree of immune cell activation changes dependent on oxygen tension surrounding the cells. An earlier study showed that T cell proliferation was maximal when cultured at $20 \%$ oxygen (Andersen et al., 1968). Recent in vitro studies culturing cells at $1-5 \%$ oxygen to reproduce cellular responses at more "physiological" oxygen levels resulted in significantly reduced $\mathrm{T}$ cell proliferation as compared to $21 \%$ oxygen (Loeffler et al., 1992; Naldini et al., 1997; Atkuri et al., 2005, 2007; Larbi et al., 2010). The less oxygenated culture condition decreased IL- 2 and IFN- $\gamma$ production from stimulated T cells (Zuckerberg et al., 1994; Caldwell et al., 2001; Kim et al., 2008; Roman et al., 2010). It was also shown that the hypoxic atmosphere decreased cytotoxic activity of NK cells (Fink et al., 2003) and retarded development of cytotoxic T cells in the mixed lymphocyte culture (Caldwell et al., 2001). Limited maturation of dendritic cells under hypoxic condition might contribute to the reduction of T cell activation (Yang et al., 2009; Wang et al., 2010).

These in vitro studies suggest that tissue hypoxia diminishes lymphocytes activation. A likely explanation for the hypoxic control of $\mathrm{T}$ cell activation involves hypoxia inducible factor- $1 \alpha$ (HIF-1 $\alpha$ ), a transcriptional factor, which facilitates adaptation to hypoxic stress by switching the energy supply from oxidative metabolism to an anaerobic pathway (Majmundar et al., 2010). Since the switch in energy metabolism considerably reduces ATP availability, HIF- $1 \alpha$ activation may be one of the reasons for the diminished lymphocyte activities under hypoxia.

Interestingly, $\mathrm{HIF}-1 \alpha$ overexpression in T cells diminished $\mathrm{Ca}^{2+}$ signaling induced by $\mathrm{T}$ cell receptor crosslink (Neumann et al., 2005). Consistent with the negative role of HIF- $1 \alpha$ in T cell activation, higher levels of IFN- $\gamma$ were observed from T cells lacking HIF-1 $\alpha$ (Lukashev et al., 2006; Guo et al., 2009). These immunosuppressive effects of HIF-1 $\alpha$ are consistent with the inhibition of $\mathrm{T}$ cell activation under hypoxia. In B cells, HIF- $1 \alpha$ plays an 
important role in normal B cell development and function (Kojima et al., 2002, 2010). However, other studies revealed an additional role for HIF- $1 \alpha$ in the control of immune cells. Since many immune cells work in inflamed tissues, which are potentially hypoxic, adaptation to hypoxic environment might be critical for their function. Accordingly, HIF-1 $\alpha$-deficient myeloid cells (granulocytes, monocytes) showed decreased activation and function (Cramer et al., 2003; Nizet and Johnson, 2009) and it was shown that in contrast to its effects in T cells, HIF-1 $\alpha$ promoted inflammatory cytokines production from macrophages (Peyssonnaux et al., 2007; Fang et al., 2009). Hypoxia could even prevent apoptosis of neutrophils (Walmsley et al., 2005).

Extracellular adenosine is another important molecule that may be involved in the mechanism of hypoxic immunosuppression in vivo (Sitkovsky et al., 2004; Sitkovsky and Ohta, 2005). Stimulation of A2A adenosine receptor (A2AR) on the cell surface is known to block activation of granulocytes, monocytes, and lymphocytes. In T cells, both $\mathrm{CD}^{+}{ }^{+}$and $\mathrm{CD}^{+}$cells are susceptible to A2AR stimulation (Ohta et al., 2009). T cell activation in the presence of adenosine attenuates proliferation, cytotoxicity, and cytokine producing activities (Ohta et al., 2009). Moreover, A2AR-deficiency was demonstrated to exaggerate proinflammatory responses and inflammatory tissue damage in vivo (Ohta and Sitkovsky, 2001). The result strongly suggests that the immunoregulatory function of endogenously produced adenosine is indispensable for the control of immune responses.

Tissue hypoxia is considered to be a trigger for the accumulation of extracellular adenosine by increasing degradation of ATP (Sitkovsky et al., 2004; Sitkovsky and Ohta, 2005). The whole body exposure of mice to hypoxic atmosphere resulted in the increase of blood adenosine levels, and strongly inhibited the induction of inflammatory tissue injury in the A2AR-dependent fashion (Choukèr et al., 2008). Tumors, which have potentially hypoxic microenvironment, were found to contain high levels of adenosine (Blay et al., 1997; Ohta et al., 2006). The adenosine-rich environment plays a role in tumors' escape from immune attack because the blockade of adenosine-A2AR pathway dramatically improved tumor regression by immune cells (Ohta et al., 2006). Thus, the adenosine-A2AR pathway seems to be involved in the mechanism of hypoxic immunosuppression, though the principal mechanism for the immunoregulation under hypoxia needs to be investigated.

Since tissue oxygen level can critically affect overall outcome of immune responses, it is of great interest to study oxygen levels in lymphoid organs. In general, oxygen availability varies among tissues and sites within the same tissue (McLaughlin et al., 1996; Braun et al., 2001; Caldwell et al., 2001; Hale et al., 2002). Direct measurements by a microelectrode demonstrated that the oxygen levels in the spleen vary between 0.5 and $4.5 \%$ probably dependent on the distance from the blood vessels (Caldwell et al., 2001). In the thymus, scattered hypoxic regions were observed in the cortex and medulla (Hale et al., 2002). These results suggest not only the presence of variable levels of oxygen in lymphoid organs but also a possibility that lymphocytes in the same organ may be exposed to different levels of oxygen dependent on their distribution.

The visualization of hypoxia became feasible with the development and improvement of techniques using nitroimidazole compounds, which form stable covalent adducts with cellular proteins under hypoxia. These compounds have been used to successfully detect hypoxia in tumors (Lord et al., 1993; Evans et al., 2000; Vukovic et al., 2001) and other organs (Arteel et al., 1995; Bergeron et al., 1999; Shabsigh et al., 2001; Koch, 2002) in experimental animals and humans. Hypoxyprobe-1 (HP-1; pimonidazole hydrochloride) is a commercially available nitroimidazole compound, which can detect hypoxia as low as $10 \mathrm{mmHg}$ oxygen. In this study, we utilized flow cytometry in analyses of hypoxic exposure of lymphocytes in vivo using HP-1. We detected different degrees of hypoxia in lymphoid organs and in lymphocyte subsets. The comparison of more and less hypoxic $\mathrm{T}$ cells revealed that $\mathrm{T}$ cells are activated less frequently in the more hypoxic tissue microenvironments.

\section{MATERIALS AND METHODS MICE}

C57BL/6 mice were purchased from Charles River Laboratories (Wilmington, MA, USA) or bred in our animal facility in the Northeastern University. Mice were used at 8-12 weeks of age. The experiments were approved by the Northeastern University Institutional Animal Care and Use Committee and were carried out in accordance with the institutional animal care guidelines.

\section{EXPOSURE TO HYPOXIC OR HYPEROXIC ATMOSPHERE}

After the intraperitoneal injection of HP-1 (100 mg/kg; HPI Inc., Burlington, MA, USA), the mice were exposed to $21 \%$ (normoxic), $8 \%$ (hypoxic), or 100\% oxygen (hyperoxic atmosphere) for $2 \mathrm{~h}$. Extended labeling time with HP-1 did not further increase the intensity of HP-1-labeled cells. This might be because of short half-life of HP-1 in mice (<30 min). The mice were placed in air-tight modular incubation chambers (Billups-Rothenberg, San Diego, CA, USA) supplied with a constant gas flow (1.5 l/min). The spleen, thymus, lymph nodes, liver and lung were excised from the mice. Axillary and inguinal lymph nodes were combined to prepare lymph node cells. Mononuclear cells from the liver and lung were prepared as described previously (Ohta and Sitkovsky, 2001). The minced liver and lung tissues were extruded through stainless steel mesh (\#200) and spun down $(450 \times g$, $5 \mathrm{~min})$. The pellet was resuspended in $40 \%$ Percoll (GE Healthcare, Upsalla, Sweden) for density centrifugation $(1,750 \times g, 10 \mathrm{~min})$. The pellet was treated with ACK lysing buffer (Invitrogen, Carlsbad, CA, USA) to remove erythrocytes.

\section{DETECTION OF HYPOXIC CELLS}

HP-1 binding was analyzed by intracellular staining followed by flow cytometry. Lymphocyte populations were discriminated by using fluorochrome-conjugated antibodies against various surface markers. PE- and allophycocyanin (APC)-conjugated antiB220, Cychrome-conjugated anti-CD4, APC-conjugated antiCD8, PE-conjugated anti-CD3, APC-conjugated anti-NK1.1, PEconjugated anti-CD69, and PE-conjugated anti-CD40 ligand (CD40L) antibodies were from BD Biosciences (San Diego, CA, USA). After cell surface staining, the cells were fixed and permeabilized using FoxP3 staining buffer set (eBioscience, San Diego, CA, USA) according to manufacturer's protocol. FITC-conjugated anti-HP-1 antibody (clone 4.3.11.3; HPI) was added at 1:1,000. The data were acquired using FACSCalibur (BD Biosciences). 


\section{T CELL ACTIVATION IN VIVO}

Mice were treated with HP-1 and various oxygen atmosphere for $2 \mathrm{~h}$ as described above. The mice received intravenous injection of concanavalin A $(10 \mathrm{mg} / \mathrm{kg})$ or anti-CD3 mAb $(50 \mu \mathrm{g} / \mathrm{ml}) 1 \mathrm{~h}$ after HP-1 injection. Two hours after HP-1, CD69, and CD40L expression on $\mathrm{T}$ cells in the spleen was analyzed together with HP-1 binding.

\section{RESULTS}

\section{VARIABLE OXYGEN TENSIONS IN LYMPHOID ORGANS}

To analyze oxygen environment of individual lymphocytes, we utilized flowcytometric detection of HP-1 binding. Spleen cells were isolated from mice $2 \mathrm{~h}$ after the injection of HP-1. Cellular binding of HP-1 was detected by FITC-labeled anti-HP-1 mAb (Figure 1A). There was a moderate level of HP-1 labeling of spleen cells as indicated by a shift $\left(21 \% \mathrm{O}_{2}\right)$ from background levels (shadowed peak). Exposure of mice to hypoxic atmosphere $\left(8 \% \mathrm{O}_{2}\right)$ significantly augmented the HP-1 labeling of spleen cells (Figure 1B). Conversely, when mice were exposed to hyperoxic atmosphere $\left(100 \% \mathrm{O}_{2}\right)$, the proportion of HP-1-labeled cells was significantly reduced (Figure 1B). The levels of HP-1-labeling correlated with the atmospheric oxygen tension indicating that this assay is capable of detecting hypoxic lymphocytes. The limitation of this assay is that HP-1 can detect hypoxia only up to $10 \mathrm{mmHg}$ $\mathrm{pO}_{2}$. Therefore, the "modestly" hypoxic cells might turn out to be negative in this assay. However, a portion of normal spleen cells $\left(21 \% \mathrm{O}_{2}\right)$ appeared to be more hypoxic than the rest (Figure 1A). Spleen cells distributed in a wide range of oxygen tension even after exposure to hypoxia $\left(8 \% \mathrm{O}_{2}\right)$. Indeed, most of the cells became hypoxic, while a small number of cells still remained less (or non-) hypoxic. This wide range of distribution is consistent with previous results from direct measurement using microelectrodes, which showed variable levels of oxygen in the same spleen ranging from well-oxygenated to deeply hypoxic (Braun et al., 2001; Caldwell et al., 2001).

Comparison among lymphoid organs in the same mouse showed that thymus is an exceptionally hypoxic tissue (Figure 2; Table 1). The oxygen environment in lymph nodes was similar to that of spleen although lymph nodes were slightly less hypoxic. Lymphocytes in the liver and lung were present in betteroxygenated environment. The levels of HP-1 binding, especially in the lung, dropped to levels lower than any lymphoid organs. When mice were exposed to hypoxic atmosphere $\left(8 \% \mathrm{O}_{2}\right)$, the extent of HP-1 binding increased in all tested tissues but the order of intensity remained the same (Table $\mathbf{1}$ ).

\section{DIFFERENCES IN OXYGEN EXPOSURE STATUS OF LYMPHOCYTE SUBSETS IN VIVO}

The flowcytometric assay enabled us to discriminate oxygen status in each lymphocyte subsets by combining HP-1 analysis with lineage markers. Co-staining of spleen cells with B220 showed that only $20 \%$ of $\mathrm{B} 220^{+}$cells were HP-1-positive, while approximately half of $\mathrm{B}^{2} 20^{-}$cells were hypoxic (Figure 3A). When exposed to hypoxic atmosphere, $\mathrm{HP}-1^{+}$cells increased to $45 \%$ in $\mathrm{B} 220^{+}$cells but it was more than $80 \%$ of $\mathrm{B} 220^{-}$population. This result suggested that majority of $\mathrm{B}$ cells are localized to relatively well-oxygenated environment. An inverse pattern was observed

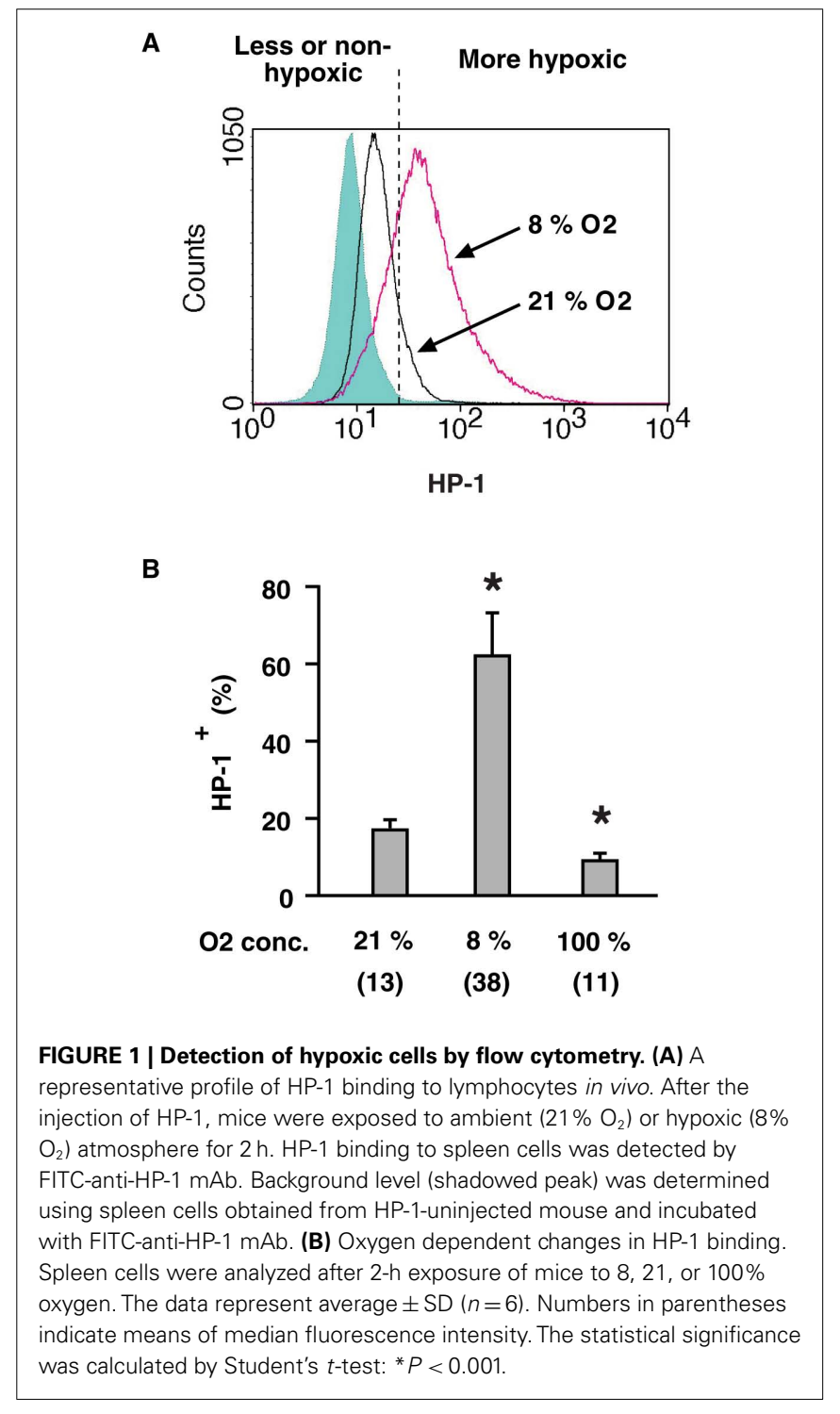

in the co-staining with CD3. The proportion of $\mathrm{HP}-1^{+}$cells was always higher in $\mathrm{CD}^{+}$cells than in $\mathrm{CD}^{-}$population (Figure $3 \mathrm{~A}$ ). Within $\mathrm{T}$ cells, $\mathrm{CD}^{+}{ }^{+}$and $\mathrm{CD}^{+}$cells showed similar intensities of HP-1 binding, which were higher than B cells (Figure 3B). The same trend was observed in lymph nodes. We further analyzed oxygen tension in other lymphocytes including NK and NKT cells. Interestingly, HP-1 intensity in NK cells was even higher than T cells (Figure 4). The HP-1 intensity in NKT cells was intermediate between $\mathrm{T}$ cells and NK cells. These results suggested that oxygen levels are not uniform to every lymphocyte subsets. In peripheral lymphoid tissues, B cells were oxygenated well. T cells and NKT cells are better oxygenated than NK cells. In the thymus, immature T cells showed different degree of HP-1 binding: $\mathrm{CD}^{-}{ }^{-} \mathrm{CD} 8^{-}$cells being the highest, followed by $\mathrm{CD} 4^{+}$and $\mathrm{CD} 8^{+}$ single positive cells, and the lowest in $\mathrm{CD} 4^{+} \mathrm{CD} 8^{+}$population (data not shown).

Since lymphocyte subsets showed various levels of HP-1 binding, tissue-specific difference in the proportion of these subsets 

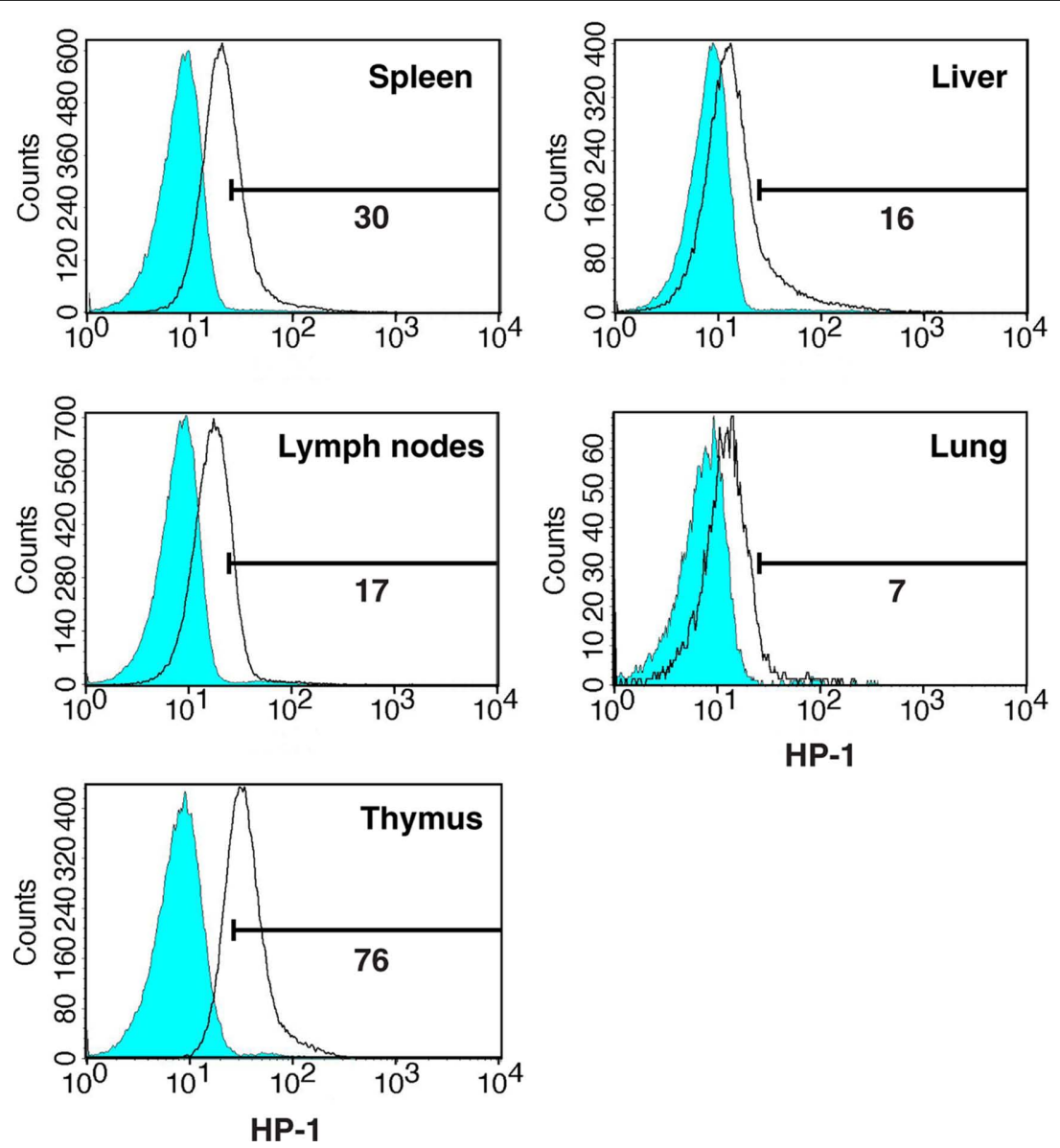

FIGURE 2 | Degree of hypoxia in lymphocytes in different organs. Mice were treated as described in Figure 1. The spleen, lymph nodes, thymus, liver,

and lung were excised and analyzed for HP-1 binding to the cells. Background levels (shadowed peaks) are the staining of cells from HP-1-uninjected mice.

Table 1 | Differences in HP-1 binding levels.

\begin{tabular}{|c|c|c|c|c|c|}
\hline & \multicolumn{4}{|c|}{$21 \% \mathrm{O}_{2}$} & \multirow{2}{*}{$\begin{array}{l}8 \% \mathrm{O}_{2} \\
\text { Total }\end{array}$} \\
\hline & Total & $\mathrm{CD}^{+}$ & $\mathrm{CD8}^{+}$ & ${\mathrm{B} 220^{+}}^{+}$ & \\
\hline Spleen & 19 & 22 & 25 & 17 & 31 \\
\hline Lymph nodes & 16 & 20 & 23 & 13 & 23 \\
\hline Liver & 14 & 17 & 17 & 10 & 19 \\
\hline Lung & 12 & 13 & 15 & 9 & 17 \\
\hline Thymus & 28 & - & - & - & 42 \\
\hline
\end{tabular}

Median fluorescence intensity was shown for total lymphocytes, $C D 4^{+}, C D 8^{+}$ and $\mathrm{B}_{22 \mathrm{O}^{+}}$cells. (Median fluorescence intensity of HP-1 uninjected cells: 7-8).

might have affected the total levels of HP-1 binding in Figure 2. To confirm the difference in tissue oxygenation levels, we further analyzed $\mathrm{B} 220^{+}, \mathrm{CD} 4^{+}$, and $\mathrm{CD} 8^{+}$cells in different organs (Table 1). In all tested organs, T cells showed higher levels of HP-1 binding than $\mathrm{B}$ cells. The binding intensities in each subset were variable between the tissues. In consistent to the total cell analysis, HP-1 binding in B cells and T cells decreased in the following order: spleen $>$ lymph nodes $>$ liver $>$ lung (Table 1 ). This result supports an implication that immune cells are exposed to different levels of oxygen dependent on the tissue.

\section{MODULATION OF T CELL ACTIVATION BY OXYGEN TENSION IN VIVO}

To test effects of oxygen tension on $\mathrm{T}$ cell activation in vivo, we monitored activation markers after the injection of Con A. Con A quickly upregulated CD69 and CD40 ligand (CD40L) on T cells; however, whole body exposure to hypoxic atmosphere inhibited this upregulation (Figure 5A). The decrease was statistically significant for both markers on $\mathrm{CD} 4^{+} \mathrm{T}$ cells and for CD69 on $\mathrm{CD}^{+} \mathrm{T}$ cells (Figure 5B). CD40L was not induced on CD8 ${ }^{+}$ $\mathrm{T}$ cells. Conversely, when mice were breathing hyperoxic atmosphere (100\% oxygen), $\mathrm{T}$ cell activation was more pronounced than at $21 \%$ oxygen. The increase was moderate in $\mathrm{CD}^{+} \mathrm{T}$ cells, but it was statistically significant in $\mathrm{CD}^{+} \mathrm{T}$ cells (Figure 5B). This experiment showed a positive correlation between oxygen tension and the extent of $\mathrm{T}$ cell activation.

Our flowcytometric assay of HP- 1 binding revealed variable levels of oxygen tension within the same cell type in the same tissue: some of them are more hypoxic than the rest. Since tissue hypoxia decreased $\mathrm{T}$ cell activation in vivo (Figure 5), we speculated that the extent of $\mathrm{T}$ cell activation might vary dependent on oxygen tension of the environment. To test this possibility, we co-injected 


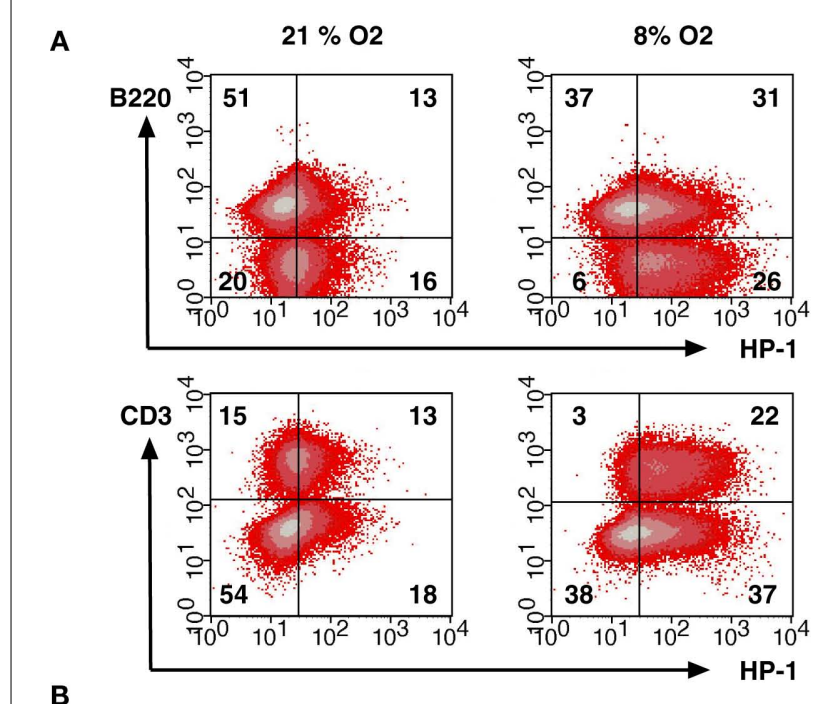

B
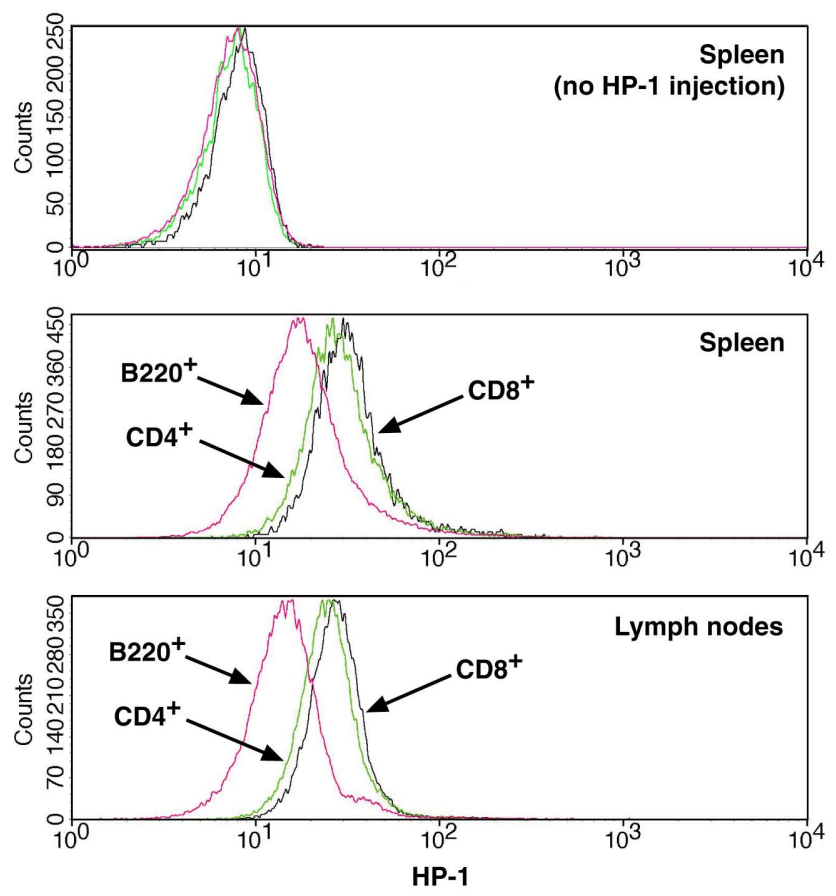

FIGURE 3 | Distribution of B cells and T cells between more and less hypoxic environment. (A) Different levels of HP-1 binding in B cells and T cells. Spleen cells from HP-1-injected mice were stained for HP-1 together with $\mathrm{PE}-a n t i-\mathrm{B} 220$ or $\mathrm{PE}-$ anti-CD3 mAb. The numbers represent percentage in each quadrant. (B) Spleen and lymph node cells were analyzed for HP-1 binding in $\mathrm{CD}^{+}, \mathrm{CD}^{+}$, and $\mathrm{B} 220^{+}$cells. Background levels were from HP-1-uninjected mice.

HP-1 with anti-CD3 mAb and analyzed CD69 expression in HP$1^{+}$and HP-1 $1^{-}$T cells. Anti-CD3 mAb induced CD69 on both $\mathrm{CD}^{+}$and $\mathrm{CD}^{+}{ }^{+}$cells, especially in less or non-hypoxic cells (Figure 6). Many of the $\mathrm{HP}-1^{-} \mathrm{T}$ cells were $\mathrm{CD}^{+} 9^{+}$; however, the proportion of $\mathrm{CD}^{+} 9^{+}$cells was smaller in $\mathrm{HP}-1^{+} \mathrm{T}$ cells. Percentage of $\mathrm{CD} 9^{+}$cells was significantly lower in $\mathrm{HP}-1^{+}$cells for both $\mathrm{CD}^{+}$and $\mathrm{CD}^{+}$population (Figure $6 \mathrm{C}$ ). This result suggests

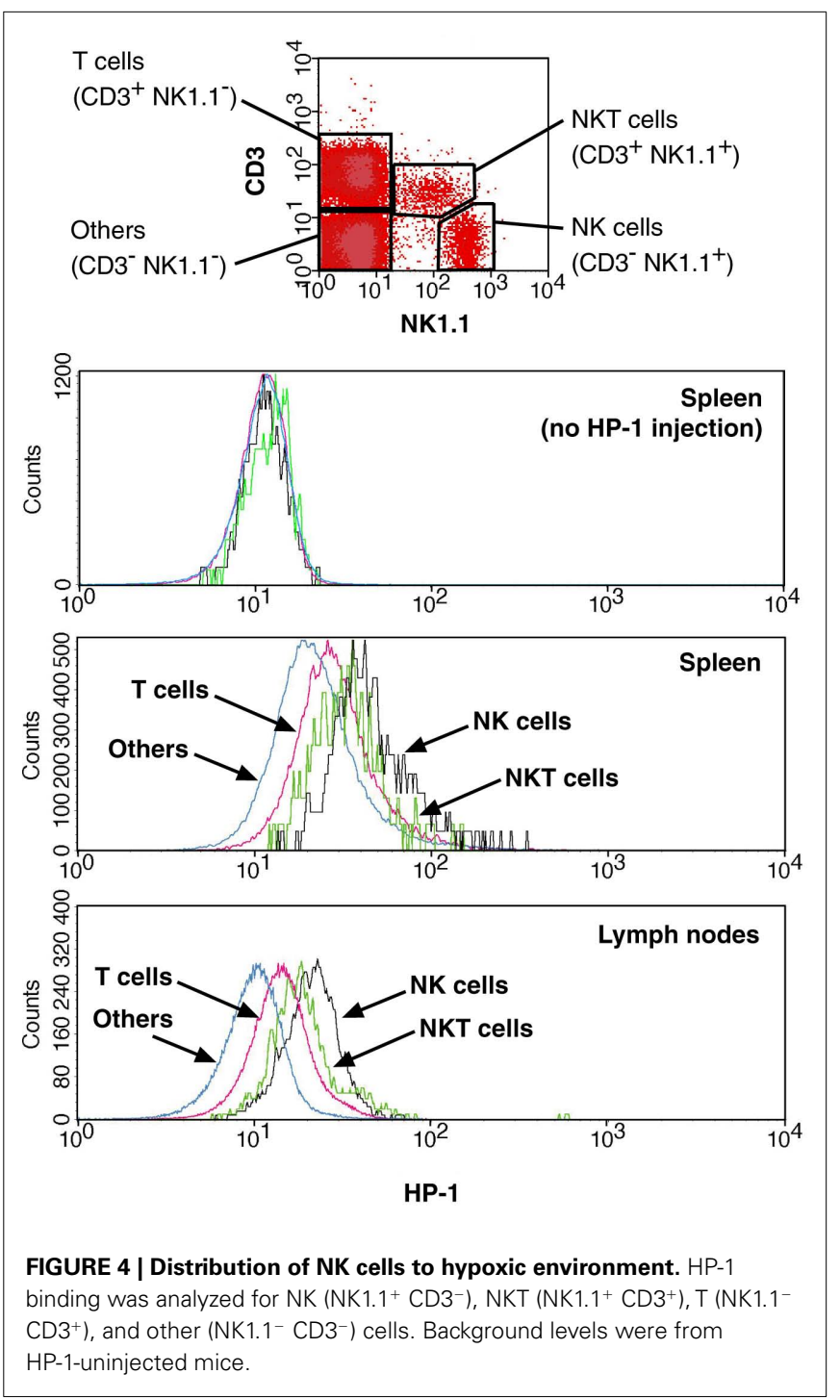

that the difference in local oxygen tension within the same tissue can affect the extent of $\mathrm{T}$ cell activation. In contrast to massive $\mathrm{T}$ cell activation in oxygenated environment, the extent of $\mathrm{T}$ cell activation decreased as the local oxygen tension lowered.

\section{DISCUSSION}

The primary purpose of this study was to compare oxygen status in lymphocytes. Flow cytometry enabled analysis of more hypoxic and less (or non-) hypoxic cells in individual lymphocyte subsets. The results revealed that oxygen levels surrounding lymphocytes vary dependent on the organs and cell types.

In the analysis of various organs, lymphocytes in the thymus were more hypoxic than in the other lymphoid organs (Figure 2; Table 1) in agreement with previous studies (McLaughlin et al., 1996; Braun et al., 2001; Hale et al., 2002). According to the measurement by microelectrodes, $\mathrm{pO}_{2}$ ranges $4-31 \mathrm{mmHg}$ in the spleen with vast majority of cells within $10-25 \mathrm{mmHg}$, while the $\mathrm{pO}_{2}$ values in the thymus were $0-17 \mathrm{mmHg}$ (Braun et al., 2001). Our assay confirmed more severe thymic hypoxia than in the 


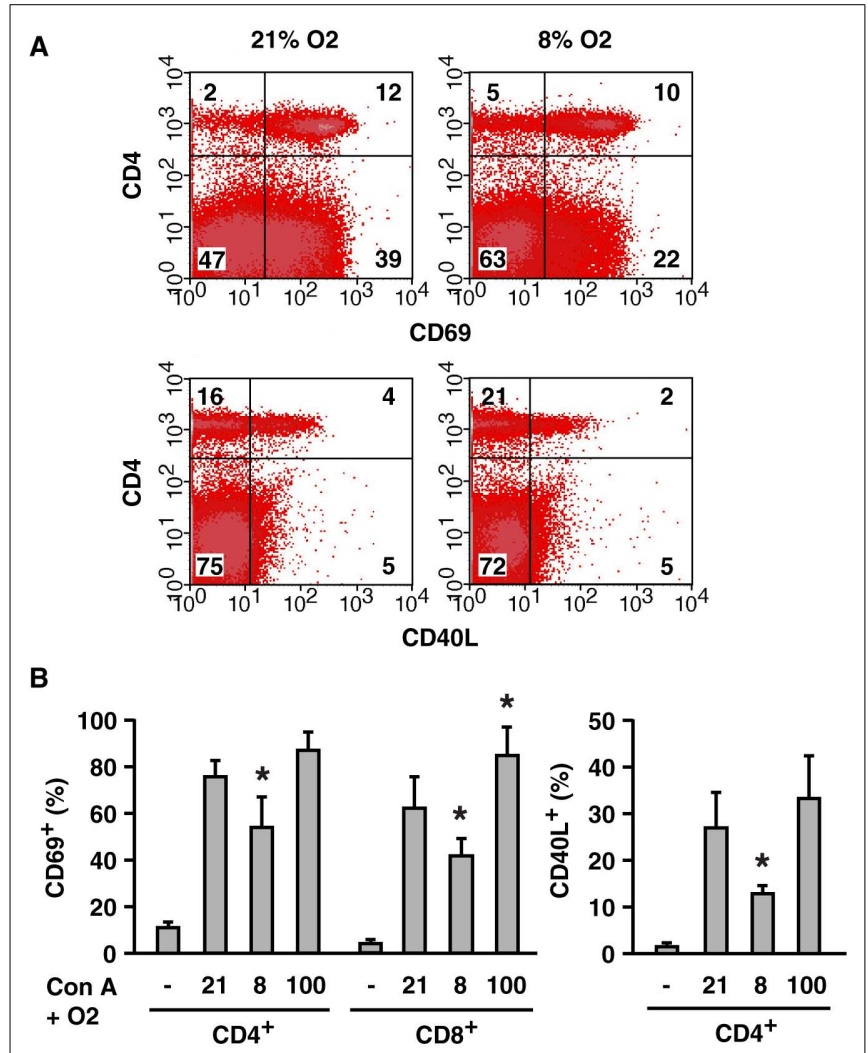

FIGURE 5 | Oxygen level-mediated regulation of T cell activation in vivo. (A) Inhibition of $\mathrm{T}$ cell activation by whole body exposure to hypoxia $\left(8 \% \mathrm{O}_{2}\right)$. CD69 and CD40L upregulation on T cells after Con A injection was analyzed. The numbers represent percentage in each quadrant. (B) Induction of CD69 and CD40L in mice exposed to different concentrations of oxygen $\left(8,21\right.$, and $\left.100 \% \mathrm{O}_{2}\right)$. Controls (-) were obtained from untreated mice (no Con $\mathrm{A}, 21 \% \mathrm{O}_{2}$ ). After the injection of Con $\mathrm{A}$, percentages of $\mathrm{CD}_{69}{ }^{+}$or $\mathrm{CD}_{40 L^{+}}$within $\mathrm{CD}^{+}$and $\mathrm{CD}^{+}$cells were calculated. The data represent average $\pm \mathrm{SD}(n=3-6)$. The statistical significance was calculated by Student's $t$-test: ${ }^{*} P<0.05$ vs $21 \% \mathrm{O}_{2}$.

spleen and detected less hypoxic environment in the lymph nodes and other peripheral organs (Figure 2; Table 1). Distribution of the cells in variable levels of oxygen tensions, which were indicated by the fluorescence intensity in our assay, also corresponded well with the results of direct measurement of $\mathrm{pO}_{2}$ levels (Braun et al., 2001; Caldwell et al., 2001). Microelectrodes detected a broad range of oxygen levels in lymphoid organs, and tissue histochemistry study showed localized immunoreactivity of anti-pimonidazole antibody in the thymus (Hale et al., 2002) suggesting anatomically variable oxygen tension within the tissue. Interestingly, the flowcytometric assay showed that oxygen environment might differ dependent on cell types in the same tissue (Figures 3 and 4). We analyzed the extent of hypoxia for individual lymphocyte subsets in peripheral lymphoid organs and found non-proportional distribution of lymphocyte subsets between more and less hypoxic area. Indeed, NK cells preferentially located in the most hypoxic area, followed by NKT cells and $\mathrm{T}$ cells. B cells were present in a well-oxygenated environment.
A caveat with the use of HP-1 is possible enzymatic reduction of the compound that may cause oxygen-independent labeling of the cells. Although studies have not recognized a case where enzymatic activity overwhelms hypoxia-dependent bindings (Parliament et al., 1992; Arteel et al., 1995, 1998), oxygenindependent non-specific binding to lymphocytes had to be tested. We incubated spleen cells with HP-1 in vitro and analyzed the binding to each lymphocyte subsets. There was not significant difference after $2 \mathrm{~h}$ of incubation; however, it became apparent after longer time that the intensity in B cells was less than T cells (data not shown). The intensities in NKT cells and NK cells were equivalent to $\mathrm{T}$ cells. This in vitro experiment suggested a possibility that B cells and other lymphocytes might have different levels of non-specific binding. In our in vivo experiments, however, the difference in HP-1 binding to T cells and B cells became even larger in mice exposed to hypoxic atmosphere (Figure 3A). If the difference between $\mathrm{T}$ cells and $\mathrm{B}$ cells was solely due to oxygen-independent non-specific binding, the difference will not be intensified under hypoxia. Therefore, although the possibility of non-specific binding cannot be excluded, B cells are likely to be better-oxygenated in vivo.

The reason for this heterogeneous distribution is not clear. Lymphocyte subsets are often located in a specific area in the tissue and this localization is important for their functions (Zandvoort and Timens, 2002; Hoek et al., 2010). It is possible that a certain range of oxygen tension may be favorable to a specific cell population. For example, $\mathrm{T}$ cells are present in an intermediate but relatively better-oxygenated condition (Figures 3 and 4). Certain levels of oxygenation may be important for $\mathrm{T}$ cell activation because this process is very susceptible to hypoxia- and adenosinemediated immunosuppression (Sitkovsky et al., 2004; Sitkovsky and Ohta, 2005). When activated under hypoxia, the resulted $\mathrm{T}$ cells might possess impaired effector functions as was observed in $\mathrm{T}$ cells activated under the influence of adenosine (Ohta et al., 2009). At the same time, however, lower levels of oxygen might decrease redox stress in T cells. T cells cultured at 5\% oxygen were found to maintain higher GSH content and GSH/GSSG ratio than in ambient atmosphere (Atkuri et al., 2005, 2007). In the thymus, its hypoxic environment in the tissue may be implicated to survival of thymocytes (McLaughlin et al., 1996). The effect of hypoxia in $\mathrm{B}$ cells is not known well. Mice and humans received immunization under hypoxia, but there was no difference in B cell functions (Meehan, 1987; Meehan et al., 1988; Biselli et al., 1991).

Hypoxic environment is immunosuppressive as in vitro studies have shown diminished $\mathrm{T}$ cell proliferation (Loeffler et al., 1992; Naldini et al., 1997; Atkuri et al., 2005, 2007; Larbi et al., 2010) and cytokines production (Zuckerberg et al., 1994; Caldwell et al., 2001; Kim et al., 2008; Roman et al., 2010). Treatment of T cells with $\mathrm{Co}^{2+}$ or desferrioxamine, which are often used to mimic hypoxia, also reduced $\mathrm{T}$ cell activation (Lederman et al., 1984; Carotenuto et al., 1986; Chaudhri et al., 1986; Wang et al., 1996; Pae et al., 2004). We previously reported that whole body exposure of mice to hypoxic atmosphere blocked the induction of inflammatory tissue injury and accompanying cytokines production (Choukèr et al., 2008). In humans, in addition to the inhibition of T cell activation (Conforti et al., 2003; Robbins et al., 2005), whole body exposure to hypoxia was reported to decrease 

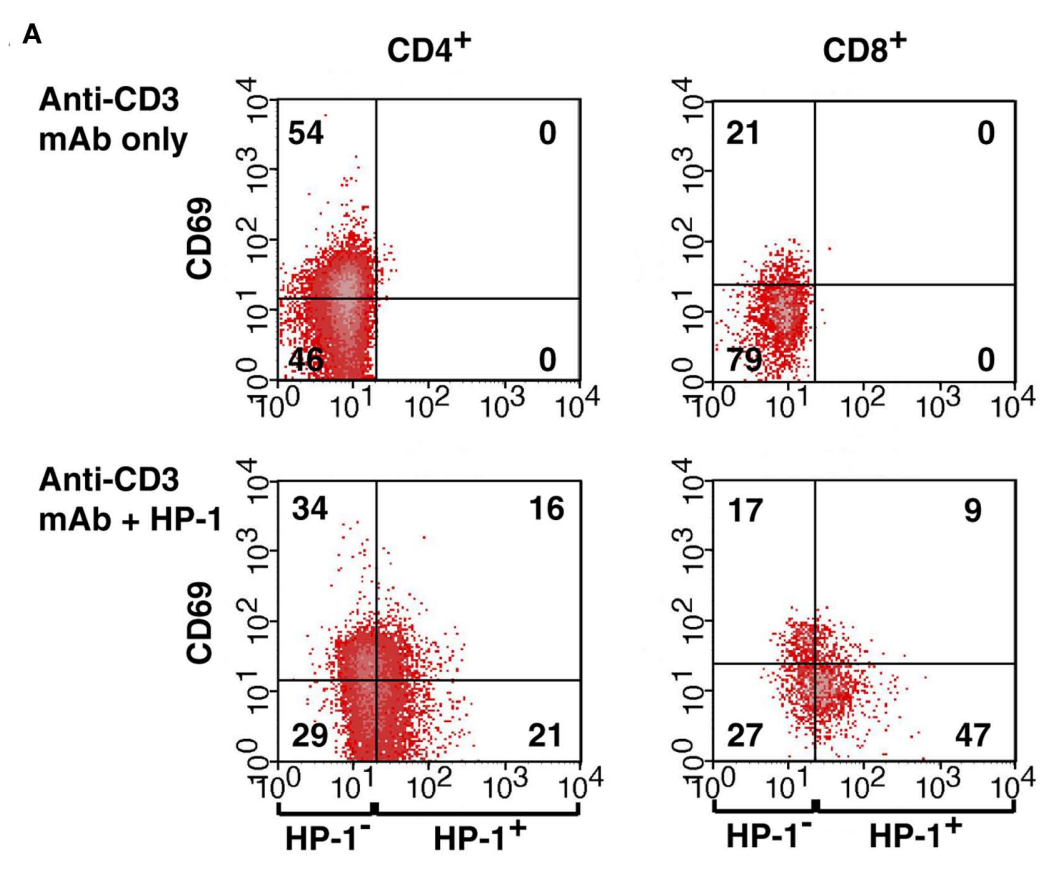

B
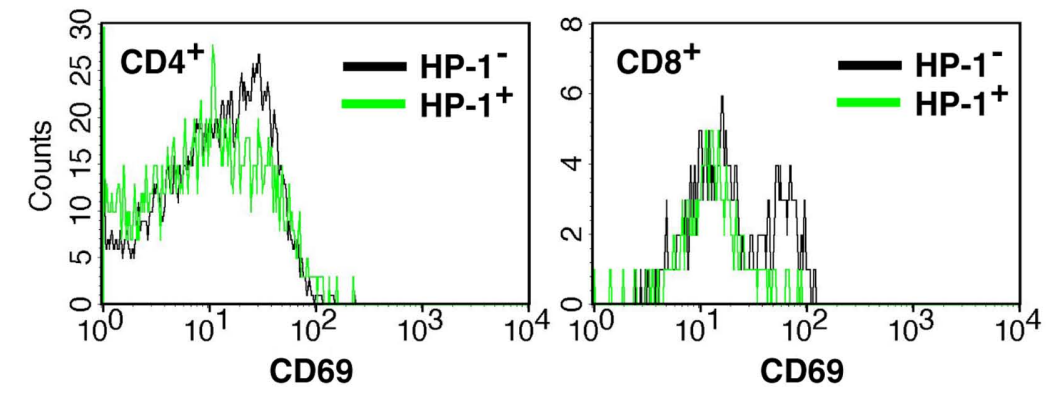

C

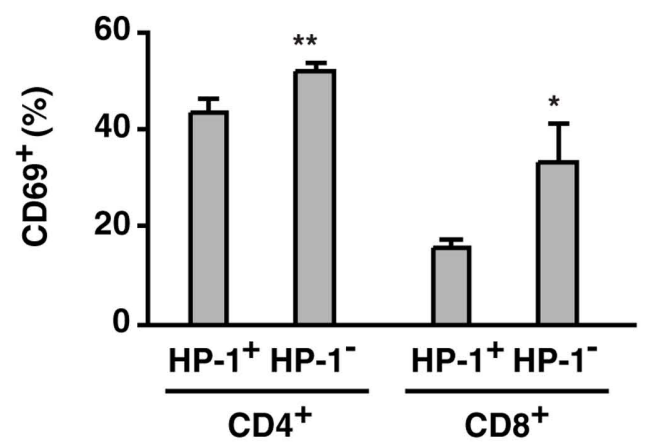

FIGURE 6 | Preferential activation of T cells in the more oxygenated environment. (A) Correlation of CD69 upregulation with local oxygen levels. Mice received co-injection of HP-1 and anti-CD3 mAb, and CD69 induction on T cells was separately analyzed in $\mathrm{HP}_{-1-}^{-}$and $\mathrm{HP}_{-1}{ }^{+}$ cells. The numbers represent percentage in each quadrant.

(B) Comparison of CD69 expression in $\mathrm{HP}^{-1}{ }^{-}$and $\mathrm{HP}_{-1}{ }^{+}$cells. $\mathrm{HP}-1^{-}$ fraction contains more $\mathrm{CD}^{2} 9^{+}$cells but less $\mathrm{CD}^{-} 9^{-}$cells than $\mathrm{HP}-1^{+}$ fraction. (C) Both $\mathrm{CD} 4^{+}$and $\mathrm{CD} 8^{+}$cells showed stronger activation in the $\mathrm{HP}-1^{-}$fraction. Percentage of $\mathrm{CD} 69^{+}$cells in $\mathrm{CD} 4^{+}\left(\mathrm{CD} 8^{+}\right)$ population was calculated. The data represent average $\pm \operatorname{SD}(n=4)$. The statistical significance was calculated by Student's $t$-test: ${ }^{*} P<0.01$; ${ }^{*} P<0.001$.
T cell functions (Meehan, 1987; Meehan et al., 1988). While these data support the immunosuppressive role of hypoxia, the opposite observations have been also reported where hypoxia enhanced $\mathrm{T}$ cell proliferation in vitro (Krieger et al., 1996; Carswell et al., 2000). This contradiction could be resolved by determining the effect of hypoxia on $\mathrm{T}$ cell response in vivo. In the current study, $\mathrm{T}$ cell 
activation, as indicated by CD69 and CD40L upregulation, positively correlated with oxygen concentration in the atmosphere (Figure 5). Diversity of oxygen environment within the same organ (Figures 3 and 4) prompted us to compare T cell activation in more and less hypoxic area. The result showed that response to activating stimuli was more extensive in better-oxygenated cells (Figure 6).

Although there was a correlation between local oxygen tension and extent of $\mathrm{T}$ cell activation, some $\mathrm{T}$ cells in less hypoxic area were still negative for CD69, while a certain number of HP-1 ${ }^{+}$ $\mathrm{T}$ cells managed to activate. In the current analysis, some of the hypoxic cells might have appeared HP-1-negative. Nitroimidazole compounds can detect hypoxic cells when oxygen concentration is as low as $1 \%$. However, in vitro studies have shown that oxygen deprivation limits $\mathrm{T}$ cell activation even at 2-5\% oxygen (Naldini et al., 1997; Atkuri et al., 2005, 2007; Larbi et al., 2010), and these levels of hypoxia are not detectable by HP-1. Therefore, if $\mathrm{T}$ cells are exposed to this intermediate level of hypoxia, their activation may well be suppressed but the cells will appear HP-1-negative. Another possible explanation is the traffic of lymphocytes. We allowed $2 \mathrm{~h}$ after the injection of HP-1. During which time, there might be a bidirectional cellular traffic between more hypoxic and less hypoxic areas. If it were the case, once they visited more hypoxic area in these $2 \mathrm{~h}$, the cells would be labeled by HP-1 no matter where they were present at the moment of activation. Although the assay might have overestimated the number of severely hypoxic cells, it is interesting that we could still observe a difference in cell activation between more and less hypoxic cells.

Immunosuppression under hypoxia has pathophysiological implications. Active inflammation destroys blood vessels and makes the damaged tissue hypoxic. Correspondingly, tissue hypoxia in various inflammation was demonstrated previously (Niinikoski et al., 1972; Peters et al., 2004; Thiel et al., 2007). This reaction can diminish proinflammatory activities of immune cells

\section{REFERENCES}

Andersen, V., Hellung-Larsen, P., and Sorensen, S. F. (1968). Optimal oxygen tension for human lymphocytes in culture. J. Cell. Physiol. 72, 149-152.

Arteel, G. E., Thurman, R. G., and Raleigh, J. A. (1998). Reductive metabolism of the hypoxia marker pimonidazole is regulated by oxygen tension independent of the pyridine nucleotide redox state. Eur. J. Biochem. 253, 743-750.

Arteel, G. E., Thurman, R. G., Yates, J. M., and Raleigh, J. A. (1995). Evidence that hypoxia markers detect oxygen gradients in liver: pimonidazole and retrograde perfusion of rat liver. Br. J. Cancer 72, 889-895.

Atkuri, K. R., Herzenberg, L. A., and Herzenberg, L. A. (2005). Culturing at atmospheric oxygen levels impacts lymphocyte function. Proc. Natl. Acad. Sci. U.S.A. 102, 3756-3759.

Atkuri, K. R., Herzenberg, L. A., Niemi, A. K., Cowan, T., and
Herzenberg, L. A. (2007). Importance of culturing primary lymphocytes at physiological oxygen levels. Proc. Natl. Acad. Sci. U.S.A. 104, 4547-4552.

Bai, A., Higham, E., Eisen, H. N., Wittrup, K. D., and Chen, J. (2008). Rapid tolerization of virus-activated tumor-specific CD8 $+\mathrm{T}$ cells in prostate tumors of TRAMP mice. Proc. Natl. Acad. Sci. U.S.A. 105, 13003-13008.

Bergeron, M., Evans, S. M., Sharp, F. R., Koch, C. J., Lord, E. M., and Ferriero, D. M. (1999). Detection of hypoxic cells with the 2-nitroimidazole, EF5, correlates with early redox changes in rat brain after perinatal hypoxia-ischemia. Neuroscience 89, 1357-1366.

Biselli, R., Le Moli, S., Matricardi, P. M., Farrace, S., Fattorossi, A., Nisini, R., and D'Amelio, R. (1991). The effects of hypobaric hypoxia on specific B cell responses following immunization in mice and humans. Aviat. Space Environ. Med. 62, 870-874.

and prevent excessive tissue damage, which might result in critical tissue dysfunction, if uncontrolled. The importance of negative feedback from hypoxia-adenosine-mediated immunoregulation was demonstrated at least in part by much exaggerated inflammatory tissue damage in A2AR-deficient mice (Ohta and Sitkovsky, 2001; Sitkovsky et al., 2004; Sitkovsky and Ohta, 2005).

Although hypoxia can provide a protection to excessive inflammation, the same mechanism may in turn help to establish tumor microenvironment, in which anti-tumor immune responses are strongly suppressed. Correspondingly, hypoxia correlates with poor prognosis in cancer (Harris, 2002; Vaupel and Mayer, 2007). Anti-tumor immunity severely suffers from the immunosuppressive nature of tumor microenvironment, and this is a potential obstacle to overcome for successful prevention of tumor progression and elimination of tumors by immunotherapy (Gajewski et al., 2006; Bai et al., 2008; Mellor and Munn, 2008). The improvement of tumor regression in the absence of A2AR signaling suggested a promising treatment of cancer by inhibiting the hypoxia-adenosine pathway (Ohta et al., 2006). In our study, more oxygenated environment in vivo was advantageous to $\mathrm{T}$ cell activation (Figures 5 and 6) and exposure to hyperoxic atmosphere could alleviate hypoxia (Figure 1B). Moreover, exposure to hyperoxic atmosphere was shown to exaggerate inflammation (Thiel et al., 2005). Therefore, hyperoxic exposure may improve anti-tumor immune responses by the reversal of local hypoxia.

In conclusion, we found variable levels of oxygen in lymphocyte subsets within the same organ. The levels of tissue oxygenation may critically affect overall immune response. Our results suggest management of oxygen levels as a possible intervention against diseases of hypoxic tissues, e.g., cancer and inflammation.

\section{ACKNOWLEDGMENTS}

This work was supported by the National Institutes of Health grants R01 CA112561 and R01 CA111985 (to MS).

Blay, J., White, T. D., and Hoskin, D. W. (1997). The extracellular fluid of solid carcinomas contains immunosuppressive concentrations of adenosine. Cancer Res. 57, 2602-2605.

Braun, R. D., Lanzen, J. L., Snyder, S. A., and Dewhirst, M. W. (2001). Comparison of tumor and normal tissue oxygen tension measurements using OxyLite or microelectrodes in rodents. Am. J. Physiol. Heart Circ. Physiol. 280, H2533-H2544.

Caldwell, C. C., Kojima, H., Lukashev, D., Armstrong, J., Farber, M., Apasov, S. G., and Sitkovsky, M. V. (2001). Differential effects of physiologically relevant hypoxic conditions on $\mathrm{T}$ lymphocyte development and effector functions. J. Immunol. 167, 6140 6149.

Carotenuto, P., Pontesilli, O., Cambier, J. C., and Hayward, A. R. (1986). Desferoxamine blocks IL 2 receptor expression on human $\mathrm{T}$ lymphocytes. J. Immunol. 136, 2342-2347.
Carswell, K. S., Weiss, J. W., and Papoutsakis, E. T. (2000). Low oxygen tension enhances the stimulation and proliferation of human $\mathrm{T}$ lymphocytes in the presence of IL-2. Cytotherapy 2, 25-37.

Chaudhri, G., Clark, I. A., Hunt, N. H., Cowden, W. B., and Ceredig, R. (1986). Effect of antioxidants on primary alloantigen-induced $\mathrm{T}$ cell activation and proliferation. J. Immunol. 137, 2646-2652.

Choukèr, A., Thiel, M., Lukashev, D., Ward, J. M., Kaufmann, I., Apasov, S., Sitkovsky, M. V., and Ohta, A. (2008). Critical role of hypoxia and A2A adenosine receptors in liver tissue-protecting physiological antiinflammatory pathway. Mol. Med. 14, 116-123.

Conforti, L., Petrovic, M., Mohammad, D., Lee, S., Ma, Q., Barone, S., and Filipovich, A. H. (2003). Hypoxia regulates expression and activity of Kv1.3 channels in T lymphocytes: a possible role in $\mathrm{T}$ cell proliferation. J. Immunol. 170, 695-702. 
Cramer, T., Yamanishi, Y., Clausen, B. E., Förster, I., Pawlinski, R., Mackman, N., Haase, V. H., Jaenisch, R., Corr, M., Nizet, V., Firestein, G. S., Gerber, H. P., Ferrara, N., and Johnson, R. S. (2003). HIF-lalpha is essential for myeloid cell-mediated inflammation. Cell 112, 645-657.

Evans, S. M., Hahn, S., Pook, D. R., Jenkins, W. T., Chalian, A. A., Zhang, P., Stevens, C., Weber, R., Weinstein, G., Benjamin, I., Mirza, N., Morgan, M., Rubin, S., McKenna, W. G., Lord, E. M., and Koch, C. J. (2000). Detection of hypoxia in human squamous cell carcinoma by EF5 binding. Cancer Res. 60, 2018-2024.

Fang, H. Y., Hughes, R., Murdoch, C., Coffelt, S. B., Biswas, S. K., Harris, A. L., Johnson, R. S., Imityaz, H. Z., Simon, M. C., Fredlund, E., Greten, F. R., Rius, J., and Lewis, C. E. (2009). Hypoxia-inducible factors 1 and 2 are important transcriptional effectors in primary macrophages experiencing hypoxia. Blood 114, 844-859.

Fink, T., Ebbesen, P., Koppelhus, U., and Zachar, V. (2003). Natural killer cell-mediated basal and interferonenhanced cytotoxicity against liver cancer cells is significantly impaired under in vivo oxygen conditions. Scand. J. Immunol. 58, 607-612.

Gajewski, T. F., Meng, Y., and Harlin, H. (2006). Immune suppression in the tumor microenvironment. $J$. Immunother. 29, 233-240.

Guo, J., Lu, W., Shimoda, L. A., Semenza, G. L., and Georas, S. N. (2009). Enhanced interferon-gamma gene expression in $\mathrm{T}$ Cells and reduced ovalbumin-dependent lung eosinophilia in hypoxia-inducible factor-1-alpha-deficient mice. Int. Arch. Allergy Immunol. 149, 98-102.

Hale, L. P., Braun, R. D., Gwinn, W. M., Greer, P. K., and Dewhirst, M. W. (2002). Hypoxia in the thymus: role of oxygen tension in thymocyte survival. Am. J. Physiol. Heart Circ. Physiol. 282, H1467-H1477.

Harris, A. L. (2002). Hypoxia - a key regulatory factor in tumour growth. Nat. Rev. Cancer 2, 38-47.

Hoek, K. L., Gordy, L. E., Collins, P. L., Parekh, V. V., Aune, T. M., Joyce, S., Thomas, J. W., Van Kaer, L., and Sebzda, E. (2010). Follicular B cell trafficking within the spleen actively restricts humoral immune responses. Immunity 33, 254-265.

Karhausen, J., Haase, V. H., and Colgan, S. P. (2005). Inflammatory hypoxia: role of hypoxia-inducible factor. Cell Cycle 4, 256-258.

Kim, H., Peng, G., Hicks, J. M., Weiss, H. L., Van Meir, E. G., Brenner, M. K., and Yotnda, P. (2008). Engineering human tumor-specific cytotoxic $\mathrm{T}$ cells to function in a hypoxic environment. Mol. Ther. 16, 599-606.

Koch, C. J. (2002). Measurement of absolute oxygen levels in cells and tissues using oxygen sensors and 2nitroimidazole EF5. Meth. Enzymol. 352, 3-31.

Kojima, H., Gu, H., Nomura, S., Caldwell, C. C., Kobata, T., Carmeliet, P., Semenza, G. L., and Sitkovsky, M. V. (2002). Abnormal B lymphocyte development and autoimmunity in hypoxia-inducible factor 1alpha deficient chimeric mice. Proc. Natl. Acad. Sci. U.S.A. 99, 2170-2174.

Kojima, H., Kobayashi, A., Sakurai, D., Kanno, Y., Hase, H., Takahashi, R., Totsuka, Y., Semenza, G. L., Sitkovsky, M. V., and Kobata, T. (2010). Differentiation stage-specific requirement in hypoxia-inducible factor-lalpharegulated glycolytic pathway during murine B cell development in bone marrow. J. Immunol. 184, 154-163.

Krieger, J. A., Landsiedel, J. C., and Lawrence, D. A. (1996). Differential in vitro effects of physiological and atmospheric oxygen tension on normal human peripheral blood mononuclear cell proliferation, cytokine and immunoglobulin production. Int. J. Immunopharmacol. 18, 545-552.

Larbi, A., Zelba, H., Goldeck, D., and Pawelec, G. (2010). Induction of HIF-1alpha and the glycolytic pathway alters apoptotic and differentiation profiles of activated human T cells. J. Leukoc. Biol. 87, 265-273.

Lederman, H. M., Cohen, A., Lee, J. W., Freedman, M. H., and Gelfand, E. W. (1984). Deferoxamine: a reversible S-phase inhibitor of human lymphocyte proliferation. Blood 64, 748-753.

Loeffler, D. A., Juneau, P. L., and Masserant, S. (1992). Influence of tumour physico-chemical conditions on interleukin-2-stimulated lymphocyte proliferation. Br. J. Cancer 66, 619-622.

Lord, E. M., Harwell, L., and Koch, C. J. (1993). Detection of hypoxic cells by monoclonal antibody recognizing 2nitroimidazole adducts. Cancer Res. 53, 5721-5726.

Lukashev, D., Klebanov, B., Kojima, H., Grinberg, A., Ohta, A., Berenfeld, L., Wenger, R. H., Ohta, A., and Sitkovsky, M. (2006). Cutting edge: hypoxia-inducible factor lalpha and its activation-inducible short isoform I.1 negatively regulate functions of $\mathrm{CD}^{+}$and $\mathrm{CD}^{+}$ $\mathrm{T}$ lymphocytes. J. Immunol. 177, 4962-4965.
Majmundar, A. J., Wong, W. J., and Simon, M. C. (2010). Hypoxiainducible factors and the response to hypoxic stress. Mol. Cell 40, 294 309.

McLaughlin, K. A., Osborne, B. A., and Goldsby, R. A. (1996). The role of oxygen in thymocyte apoptosis. Eur. J. Immunol. 26, 1170-1174.

Meehan, R., Duncan, U., Neale, L., Taylor, G., Muchmore, H., Scott, N., Ramsey, K., Smith, E., Rock, P., Goldblum, R., and Houston, C. (1988). Operation Everest II: alterations in the immune system at high altitudes. J. Clin. Immunol. 8, 397-406.

Meehan, R. T. (1987). Immune suppression at high altitude. Ann. Emerg. Med. 16, 974-979.

Mellor, A. L., and Munn, D. H. (2008). Creating immune privilege: active local suppression that benefits friends, but protects foes. Nat. Rev. Immunol. 8, 74-80.

Michiels, C. (2004). Physiological and pathological responses to hypoxia. Am. J. Pathol. 164, 1875-1882.

Naldini, A., Carraro, F., Silvestri, S. and Bocci, V. (1997). Hypoxia affects cytokine production and proliferative responses by human peripheral mononuclear cells. J. Cell. Physiol. 173, 335-342.

Neumann, A. K., Yang, J., Biju, M. P., Joseph, S. K., Johnson, R. S., Haase, V. H., Freedman, B. D., and Turka, L. A. (2005). Hypoxia inducible factor 1 alpha regulates $\mathrm{T}$ cell receptor signal transduction. Proc. Natl. Acad. Sci. U.S.A. 102, 17071-17076.

Niinikoski, J., Hunt, T. K., and Dunphy, J. E. (1972). Oxygen supply in healing tissue. Am. J. Surg. 123, 247-252.

Nizet, V., and Johnson, R. S. (2009). Interdependence of hypoxic and innate immune responses. Nat. Rev. Immunol. 9, 609-617.

Ohta, A., Gorelik, E., Prasad, S. J., Ronchese, F., Lukashev, D., Wong, M. K., Huang, X., Caldwell, S., Liu, K. Smith, P., Chen, J. F., Jackson, E. K., Apasov, S., Abrams, S., and Sitkovsky, M. (2006). A2A adenosine receptor protects tumors from antitumor $\mathrm{T}$ cells. Proc. Natl. Acad. Sci. U.S.A. 103, 13132-13137.

Ohta, A., Ohta, A., Madasu, M., Kini, R., Subramanian, M., Goel, N., and Sitkovsky, M. (2009). A2A adenosine receptor may allow expansion of $\mathrm{T}$ cells lacking effector functions in extracellular adenosine-rich microenvironments. J. Immunol. 183, 5487-5493.

Ohta, A., and Sitkovsky, M. (2001). Role of G-protein-coupled adenosine receptors in downregulation of inflammation and protection from tissue damage. Nature 414, 916-920.

Pae, H. O., Choi, B. M., Oh, G. S., Lee, M. S., Ryu, D. G., Rhew, H. Y., Kim, Y. M., and Chung, H. T. (2004). Roles of heme oxygenase1 in the antiproliferative and antiapoptotic effects of nitric oxide on Jurkat T cells. Mol. Pharmacol. 66, 122-128.

Parliament, M. B., Wiebe, L. I., and Franko, A. J. (1992). Nitroimidazole adducts as markers for tissue hypoxia: mechanistic studies in aerobic normal tissues and tumour cells. Br. J. Cancer 66, 1103-1108.

Peters, C. L., Morris, C. J., Mapp, P. I., Blake, D. R., Lewis, C. E., and Winrow, V. R. (2004). The transcription factors hypoxia-inducible factor 1alpha and Ets-1 colocalize in the hypoxic synovium of inflamed joints in adjuvant-induced arthritis. Arthritis Rheum. 50, 291-296.

Peyssonnaux, C., Cejudo-Martin, P., Doedens, A., Zinkernagel, A. S., Johnson, R. S., and Nizet, V. (2007). Cutting edge: essential role of hypoxia inducible factor-1alpha in development of lipopolysaccharideinduced sepsis. J. Immunol. 178, 7516-7519.

Robbins, J. R., Lee, S. M., Filipovich, A. H., Szigligeti, P., Neumeier, L., Petrovic, M., and Conforti, L. (2005). Hypoxia modulates early events in $\mathrm{T}$ cell receptor-mediated activation in human $\mathrm{T}$ lymphocytes via Kv1.3 channels. J. Physiol. 564, 131-143.

Roman, J., Rangasamy, T., Guo, J., Sugunan, S., Meednu, N., Packirisamy, G., Shimoda, L. A., Golding, A., Semenza, G., and Georas, S. N. (2010). T-cell activation under hypoxic conditions enhances IFNgamma secretion. Am. J. Respir. Cell Mol. Biol. 42, 123-128.

Semenza, G. L. (2003). Angiogenesis in ischemic and neoplastic disorders. Annu. Rev. Med. 54, 17-28.

Shabsigh, A., Ghafar, M. A., de la Taille, A., Burchardt, M., Kaplan, S. A., Anastasiadis, A. G., and Buttyan, R. (2001). Biomarker analysis demonstrates a hypoxic environment in the castrated rat ventral prostate gland. J. Cell. Biochem. 81, 437-444.

Sitkovsky, M. V., Lukashev, D., Apasov, S., Kojima, H., Koshiba, M., Caldwell, C., Ohta, A., and Thiel, M. (2004). Physiological control of immune response and inflammatory tissue damage by hypoxiainducible factors and adenosine A2A receptors. Annu. Rev. Immunol. 22, 657-682. 
Sitkovsky, M. V., and Ohta, A. (2005). The 'danger' sensors that STOP the immune response: the A2 adenosine receptors? Trends Immunol. 26, 299-304.

Thiel, M., Caldwell, C. C., Kreth, S., Kuboki, S., Chen, P., Smith, P., Ohta, A., Lentsch, A. B., Lukashev, D., and Sitkovsky, M. V. (2007). Targeted deletion of HIF-1alpha gene in $\mathrm{T}$ cells prevents their inhibition in hypoxic inflamed tissues and improves septic mice survival. PLoS ONE 2, e853. doi: 10.1371/journal.pone. 0000853

Thiel, M., Chouker, A., Ohta, A., Jackson, E., Caldwell, C., Smith, P., Lukashev, D., Bittmann, I., and Sitkovsky, M. V. (2005). Oxygenation inhibits the physiological tissue-protecting mechanism and thereby exacerbates acute inflammatory lung injury. PLoS Biol. 3, e174. doi: 10.1371/ journal.pbio.0030174

Vaupel, P., and Mayer, A. (2007). Hypoxia in cancer: significance and impact on clinical outcome. Cancer Metastasis Rev. 26, 225-239.

Vukovic, V., Haugland, H. K., Nicklee, T., Morrison, A. J., and Hedley, D. W. (2001). Hypoxiainducible factor-1alpha is an intrinsic marker for hypoxia in cervical cancer xenografts. Cancer Res. 61, 7394-7398.

Walmsley, S. R., Print, C., Farahi, N., Peyssonnaux, C., Johnson, R. S., Cramer, T., Sobolewski, A., Condliffe, A. M., Cowburn, A. S., Johnson, N., and Chilvers, E. R. (2005). Hypoxia-induced neutrophil survival is mediated by HIF-1alpha-dependent NF-kappaB activity. J. Exp. Med. 201, 105-115.

Wang, J. Y., Tsukayama, D. T., Wicklund, B. H., and Gustilo, R. B. (1996). Inhibition of $\mathrm{T}$ and $\mathrm{B}$ cell proliferation by titanium, cobalt, and chromium: role of IL-2 and IL-6. J. Biomed. Mater. Res. 32, 655-661.

Wang, Q., Liu, C., Zhu, F., Liu, F., Zhang, P., Guo, C., Wang, X., Li, H., Ma,
C., Sun, W., Zhang, Y., Chen, W., and Zhang, L. (2010). Reoxygenation of hypoxia-differentiated dentritic cells induces Th1 and Th17 cell differentiation. Mol. Immunol. 47, 922-931.

Yang, M., Ma, C., Liu, S., Sun, J., Shao, Q., Gao, W., Zhang, Y., Li, Z., Xie, Q., Dong, Z., and Qu, X. (2009). Hypoxia skews dendritic cells to a $T$ helper type 2-stimulating phenotype and promotes tumour cell migration by dendritic cell-derived osteopontin. Immunology 128, e237-e249.

Zandvoort, A., and Timens, W. (2002). The dual function of the splenic marginal zone: essential for initiation of anti-TI-2 responses but also vital in the general first-line defense against blood-borne antigens. Clin. Exp. Immunol. 130, 4-11.

Zuckerberg, A. L., Goldberg, L. I., and Lederman, H. M. (1994). Effects of hypoxia on interleukin-2 mRNA expression by $\mathrm{T}$ lymphocytes. Crit. Care Med. 22, 197-203.
Conflict of Interest Statement: The authors declare that the research was conducted in the absence of any commercial or financial relationships that could be construed as a potential conflict of interest.

Received: 07 April 2011; accepted: 21 June 2011; published online: 05 July 2011.

Citation: Ohta A, Diwanji R, Kini R, Subramanian $M$, Ohta $A$ and Sitkovsky $M$ (2011) In vivo T cell activation in lymphoid tissues is inhibited in the oxygenpoor microenvironment. Front. Immun. 2:27. doi: 10.3389/fimmu.2011.00027

This article was submitted to Frontiers in $T$ Cell Biology, a specialty of Frontiers in Immunology.

Copyright (๑) 2011 Ohta, Diwanji, Kini, Subramanian, Ohta and Sitkovsky. This is an open-access article subject to a nonexclusive license between the authors and Frontiers Media SA, which permits use, distribution and reproduction in other forums, provided the original authors and source are credited and other Frontiers conditions are complied with. 